\title{
Critical Incident Stress Debriefing following the Terrorist Bombing at Army Headquarters Northern Ireland
}

\author{
Maj AP Finnegan \\ MSc,BN,CPN(Cert),QARANC \\ Community Psychiatric Nurse
}

Sgt PA Cumming

RMN,CPN(Cert), QARANC

Community Psychiatric Nurse

\section{Lt Col ME Piper}

LMSSA,MRCPsych,RAMC

Consultant Psychiatrist

Stress \& Trauma Clinic, HQNI,BFPO 825

SUMMARY: On the 7 October 1996 the Provisional Irish Republican Army launched a terrorist attack within Northern Ireland. This paper provides a descriptive reflective account of the psychological support and Critical Incident Stress Debriefings (CISD) provided for civilian/ military personnel and service families. Between 66 hours and 96 hours following the incident, 407 people were debriefed.

\section{Introduction}

CISD is a small part in the continuum of trauma care. This paper does not examine other factors such as pre trauma interventions including mental health screening and risk assessment or other post trauma care such as treatment for Post Traumatic Stress Disorder (PTSD). This paper aims to present an innovative and inductive clinical practice designed to meet an operational need and is not submitted as a research paper. However, the findings from this paper may provide a basis for empirical research at a later date.

The authors are unaware of any previous documented papers where CISDs were offered to such a large number in a specified time period. The following account initially reviews the disaster and CISDs, then progresses to describe the organisation of the debriefings. Finally there is a critical analysis of the debriefing procedure and future recommendations.

\section{Bombing at Army Headquarters, Northern Ireland}

Two $8001 \mathrm{lb}$ bombs were detonated without warning within the British Army Northern Ireland Headquarters in Thiepval Barracks, Lisburn. The first bomb exploded near the main fuel pumps with the aim of causing massive disruption. The second bomb detonated fifteen minutes later in a vehicle placed next to the garrison medical centre and kindergarten (Fig 1). This device was aimed at medical staff and rescuers. One soldier was killed, three more seriously injured, and a further twenty soldiers and five civilians evacuated to local hospitals. In addition, there were several dozen people who sustained minor injuries and medical centre staff who were not included in these initial figures.

There were more than 500 people in Thiepval Barracks, and except for those performing essential duties, the remaining military personnel, civilians and families werext evacuated to a safe area. These personnel were detainecof within camp over the next four hours whilst security checks were undertaken.

\section{Critical Incident Stress Debriefing}

CISD were initially reported during the Second Worlche War $(1,2)$. CISD is a formal group meeting for people involved in a common disaster. CISDs provide an opportunity to develop a complete picture of the event whilst exploring feelings and thoughts. Most importantly, CISDs normalise a traumatic event with the understanding that a multiplicity of symptoms can develop. For example, individuals involved in this terrorist incident reported many different recollections of the bombing whilst presenting a commonality in the feelings such as confusion and thoughts such as fear. Therefore group members were able to recognise how individuals react in different ways whilst sharing common emotions and cognitions. This allows members to identify their coping mechanisms, whilst gaining information concerning potential problems and how to access future support if required. The aims of CISD are in Table 1(3).

\section{Table 1}

\section{THE AIM OF CISD}

- Help the survivor to come to terms with the traumatic event.

- Provide survivors with details of normal stress reactions.

- Reduce stigma associated with mental health interventions.

- Provide a pathway for further support, if required. 


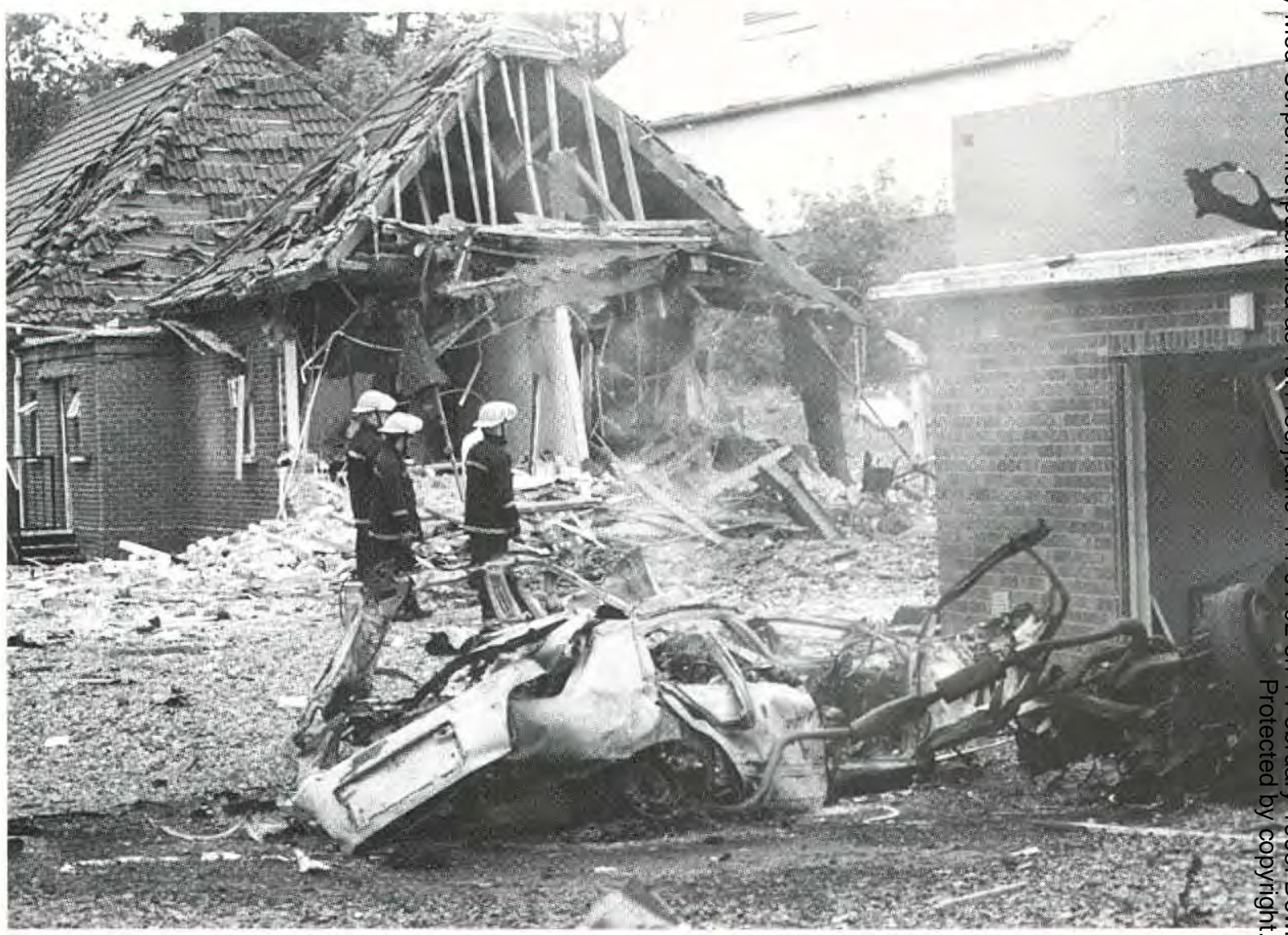

There is no empirical evidence to prove that CISD prevents post trauma psychological problems such as PTSD (4). However, there are various accounts where trauma victims have reported the debriefing to have been useful as a format for allowing open discussion with colleagues, enhancing group cohesion, knowing that support is available if required, improving self confidence and assisting them to deal with the stress associated with a traumatic event $(5,6)$. These reports concur with the authors clinical experiences.

\section{Organising the Debriefings}

The first and third authors were in Thiepval Barracks at the time of the bombings and were evacuated into a safe area. During this initial period, a venue for later debriefings was identified and a public announcement made stating dates and aim of the debriefings. Over the next two days, leaflets advertising the location and timings, together with relevant information concerning normal stress reactions were distributed to all unit service personnel, civilian employees and military families. (Chart 1). One thousand leaflets were distributed through the local Sailor, Soldier, Air Force Association (SSAFA) representative. Other support services agreed to b® available for the CISD, these being local social an welfare services together with a health visitor.

\section{Identifying Groups to be Debriefed}

The day following the bombing, the first author visite the walking wounded at the Musgrave Park Hospita (MPH) in Belfast. This provided initial contact, and chance for a defusing of the incident. This process wa helped by the medical staff at the MPH who ensured tha@ casualties received initial psychological support an information regarding the forthcoming debriefings (7).

The second author concentrated on organising the debriefings and dealing with the logistic aspects. Thi $\frac{\text { g }}{3}$ involved obtaining situation reports an video/photographic material from the bombing, whils? debriefers had to be contacted and food/accommodatio reserved. The first and second authors visited the bom site before the debriefings so that an accurate picture could be provided for the debriefers in their pre-briefing. Thä third author liaised with the senior military hierarchy tôे promote the debriefings and de-stigmatise mental healt ${ }^{\text {s }}$ intervention. 


\section{Critical Incident Stress Debriefing for Personnel Involved in the Thiepval Barracks Bombing}

A Critical Incident Debriefing will be held in the XXXXXXXXXXXXX at Thiepval Barracks for those involved in the bombing on Monday 07th Oct 1996. Debriefings will be held on Thursday for XXXXXX commencing from $1000 \mathrm{hrs}$. Further debriefings will be held on Friday 11 October commencing at $1000 \mathrm{hrs}$ for all other civilian/military personnel and at $1400 \mathrm{hrs}$ for families. Attendance is strongly advised as this type of debriefing may help prevent any long term difficulties that are occasionally associated with this type of event.

Following involvement in a major trauma an individual may experience various difficulties. Table One describes some of the common characteristics associated with this type of event. It must be stressed that these symptoms are normal reactions to an abnormal event and usually pass within a number of days. If you are still having difficulties after four weeks or if you are concerned then you should contact your medical officer. Further details will be provided at the debriefings.

\section{Table One}

Common Normal Stress Reactions (may include)

- Irritability;

- Frustration at not having achieved more;

- Recurrent memories of the event;

- Disappointment;

- Feeling anxious;
- Feeling angry;

- Self-doubt;

- Being on edge or watchful;

- Daydreaming of thinking of the incident;

- Some sleep disturbance.

More Serious Reactions Include:

- Distancing oneself and becoming more withdrawn from families \& friends;

- Marked sleep disturbance \& nightmares that continue in intensity over a period of time;

- Behavioural changes, such as having an urge to hide problems through high alcohol intake.

Remember, acute stress reactions may be distressing but are normal, and usually quickly resolves within a shor period.

Chart 1. Letter Issued to Those Involved in the Army Northern Ireland HQ Bombing.

\section{The Debriefers}

The Army's Stress and Trauma Clinic in Northern Ireland organise six CISD courses per year. These courses started in 1994 and by October 1996 had trained 320 (299 military and 21 civilian) personnel in the skills of CISD. The debriefers are primarily non medical Army service personnel. The course lasts for two and a half days, and combines lectures with provision for each attendee to be involved in eight role play debriefings. Following the bombing, 32 debriefers were contacted and agreed to participate.

Before the debriefings commenced, the debriefers were shown photographs and videos of the event. It was recognised that some of the debriefers had not used their CISD skills in practice and they were therefore provided with a refresher lecture in the aims and procedure of CISD. The debriefers were given medical up-dates on those casualties still in hospital so that attendee's queries could be answered. However, these up-dates were only a general summary as not to breach medical in confidence information. Finally, any further questions were addressed.

\section{Critical Incident Stress Debriefings}

Day 1 of the CISDs targeted those obviously involved in the incident. For these debriefings the first two authors were facilitators supported by three service personnel from the aforementioned CISD course and a civilian Community
Psychiatric Nurse (CPN). Three groups were identified ans offered two hourly debriefings at $1000 \mathrm{hrs}, 1400 \mathrm{hrs}$ an $1600 \mathrm{hrs}$.

For the first debriefing session, a group of twenty were expected, however seventy arrived. This was the start of two hectic days where flexibility became essential.

On Day 1, those closest to the bombs were provided with structured debriefings averaging approximately 90 minutes in duration. Groups received an introduction stating the aims and ground rules of the debriefing (Table 2).

\section{Table 2 \\ Critical Incident Stress Debriefing Ground Rules}

- The debriefing will last for approximately 90 minutes.

- No hierarchy. All group members wore Christian name identity labels.

- No scape-goating or pointing the finger of blame.

- Every one has an equal opportunity to speak, but individual autonomy not to speak would be respected. If an individual wanted to remain in the group and just listen, then they could.

- Individuals have a right to leave the group at any time.

- Group confidences would be respected.

- Individuals informed that they may feel worse during the debriefing due to the nature of the material being covered. 
Attendees were then shown a short video of the scene following the second bombing. The volume level was kept reasonably low so as not to re-traumatise the group. The CISD then followed the stages identified by Dyregrov ( 8 ) in 1989 , this being:

- Introduction.

- Facts.

- Thoughts \& Sensory Impressions.

- Emotional Reactions.

- Normalisation/Anticipatory Guidance.

- Future Planning \& Coping.

- Disengagement.

Following the debriefings, the debriefers along with the aforementioned support services were available to deal with individual queries. Each participant was given a copy of Chart 1 with an explanation concerning normal stress reactions.

Day 2 was divided into two sessions, with military and civilian employed MOD workers in the morning and families in the afternoon. To deal with the anticipated high numbers thirty-two debriefers were available. Three more significantly involved groups were identified and an appropriate quiet location provided for these debriefings.

The format for Day 2 was slightly different. It was anticipated that groups would be less traumatised, and there was a need for efficiency to avoid unnecessary delay. The authors were unaware of previous papers concerning large debriefings in such a limited time span and there was concern over control and timings. As such, these groups did not see a video of the event. Additionally, the groups contained seven people allocated on an ad hoc basis. It was felt that to delay the groups until seven from a similar setting were together would lead to confusion and frustration, therefore causing more hindrance than help. Support "services were again available following completion of the debriefings.

The organisers had expected a good response and therefore the need for 32 debriefers. A large venue for the debriefings was identified in that thirteen separate debriefings could occur simultaneously, therefore allowing 91 attendees to be debriefed at the same time. Each group was distanced to maintain a sense of proximity but not to be restrictive to other groups. The debriefings commenced at $1000 \mathrm{hrs}$ and by $1010 \mathrm{hrs}$ the location was full with approximately 200 people waiting to be debriefed. Hot drinks were provided for those waiting.

The debriefing groups were split into two debriefers per seven clients. This was for a logistic reason in that a small group could get close in a small circle and thereby talk without having to raise their voice. As such, many groups could be debriefing in the same location at the same time without causing unnecessary distraction to other groups. This was the hypothesis and it worked extremely well with no-one reporting group distraction due to participant noise. However, nearby helicopters meant that groups did occasionally have periods of interruption.

Fewer showed up for the family debriefing with 79 attending. Lower numbers may have been influenced by other commitments such as having to collect children fromz school. Children were welcomed into the debriefings $\stackrel{\mathbb{Q}}{\mathbb{D}}$ However, the authors were unable to arrange crechen. facilities. The introduction of children into the arena did understandably increase the noise level. A health visitor? was available for queries during the afternoon.

Other sessions were provided over the next nine days for individuals who could not attend the group debriefings. In total, a further fifty-three individuals were debriefed.

\section{Critical Analysis}

Following each session, Debriefers were debriefed ande encouraged to present their impression of the $\mathrm{CISD}_{-}^{-}$ process. To maintain the flow of this paper, the debrieferscomments are now presented together with author'sc recommendations for future organisation and practise.

Positive factors identified were:

- The response from debriefed groups appeared to be? generally encouraging. Certainly, individuals in closes proximity to the bombs seemed to warmly welcome the opportunity for a debriefing;

- Attendees reported that they generally found the debriefing worthwhile. For many it was the first chance to see colleagues and friends following the incident, arde confirm their well being. As stated above, walkipign wounded were informed of the debriefings and attende्e

- The mixing of groups on day two, that is individugiso (both military and civilian) who were in different places at the time of the bombing seemed to work well. Thisco appeared to stem from sharing a common ident However, there were occasional reports to the contray (see next point).

- Debriefers view of their interventions were mixed Most debriefed groups from Day Two welcomedo individuals from different settings, but others stated thato this was not appreciated. These differing responses may have been due to the skill of the debriefers or individualo participant idiosyncrasy. However, the aims of CISD were still achieved without coercing or enforcing individuals to attend (See below).

- It appeared that worthwhile debriefings were possible for a large number of people within a short time period.

Negative factors were:

- Some clients felt they had to attend a debriefing. Thiso did not appear to be a factor for those directly involved but did become an issue for some individuals on the fringes. This feeling of paternalistic intervention causect frustration and anger towards the system, and in certain cases devalued the debriefing by placing pressure on other group members to remain quiet.

If an individual is certain that he or she will not benefits. from a debriefing then he or she should have the option to refrain. In such circumstances, the value of a handoutro will provide health education and direction regarding future difficulties should problems present later.

- Identifying and contacting debriefers was extremelyew time consuming and frustrating. A registry of debriefers? is kept within the Community Mental Healthe 
Department. However the military is a transient population and many of the trained critical incident stress debriefers were not available for reasons such as having left the Province or educational courses. It demonstrated the need for a central registry detailing debriefer's availability and whereabouts. The team had anticipated such problems but lack of IT equipment and clerical support made organisation difficult.

In future, debriefers will be requested to contact the department to state their availability.

- Contingency plans to deal with disasters must be adequately formulated. The authors form the Northern Ireiand Community Mental Health Team and had to attempt to keep the department functioning normally as well as organise and facilitate the debriefings. Understandably, the routine demands on the department increased markedly during the first week. There is a need for support on the ground.

- Some of the debriefers felt de-skilled due to the timespan between training course and using their CISD skills. It highlighted the need for a regular refresher/ update course.

\section{Conclusion}

This paper has outlined the organisation of a large scale CISD in a specified time following a major disaster. On this occasion, the feedback from the CISD attendees was predominantly positive. This may be due to factors such as those clients who did not appreciate the debriefings have not presented their case but the authors are unable to investigate this at the time of going to press.

This article has been completed four months post bombing and the authors had anticipated increased referrals/enquiries to the mental health department. However, this has not happened. To date, the department has dealt with four referrals, and each of these unit members has remained in work. Again, there are a multiplicity of reasons for this such as the perceived need to soldier on in difficult circumstances, to show a brave face or simply that few are traumatised. However, being part of the community within Thiepval Barracks leads the authors to suspect that normalisation of the event ensured that traumatised individuals are aware that some emotional distress within the first weeks is common. The feedback from unit personnel is that they accept their recent feelings as a normal response and have therefore used primary coping mechanisms together with family/culture support to process their feelings.

This incident did provide an opportunity for an in-depth research study. Military attendees will be referred to the authors' department for further care should problems continue or develop and therefore structured follow up studies could be undertaken. As such, the team could have used psychometric questionnaires such as the Impact of Events Scale (9) and the General Health Questionnaire (10) as indices to levels of emotional distress. However, there is an essential ethical question to consider, that being, if the aim of the CISD is to normalise the event then the act of quizzing clients to undertake mental health research sits uneasily, as it may be seen as voyeuristic and therefore increase stigmatisation. On this occasion, research would have reinforced the idea of a psychiatric model within the debriefings that was contradictory to the aims of intervention.

There is a need for sound research methodology and epidemiological investigation but the authors feel that this requires the support of the participant group prior to a trauma and not retrospectively. From a management perspective, CISDs have been supported by the senior echelons of the Army hierarchy within Northern Ireland who have been keen to demonstrate an organisational commitment to mental health support.

From an operational perspective it has been indicated that CISD may prove beneficial by reducing absenteeism and sick leave whilst improving morale (8). In the four months following this terrorist incident there are no reports of military personnel having sick leave due to psychological reasons. In addition, no days have been lost through absenteeism whilst the authors' subjective impression gained by talking to service personnel involved in the incident is that morale has not been negatively affected. These findings have important implications in that whilst not proving that CISDs have been effective it would suggest that CISDs have not been harmful.

There are several potential reasons for these findings other than suggesting the effectiveness of the CISD. There may have been somatic type presentation in primary care Additionally, the military's medical infrastructure denotes that service personnel serving in Northern Ireland have been assessed as being physically and mentally fit and therefore personnel involved in the Thiepval bombing may? be less vulnerable to developing long term post traumatic stress problems. As such, it could be argued that current mental health screening is effective. However, the military group in this incident represent a stratified sample and the authors recognise that any conclusions are anecdotal. These findings do not diminish the need for empirical research based on prospective studies. In addition, this paper merely reflects a small segment in traumatology care and does not assess the importance of pre trauma interventions such as mental health screening and risk assessment. Also, societal and cultural factors may influence service personnel to avoid mental health support (11).

It is questionable whether CISD will reduce any long term psychiatric problems $(4,12)$. However, CISD does provide an opportunity for a group of people to discuss their recent traumatic experience in a safe setting, to receive information regarding normal post trauma stress reactions, and be informed of a pathway for further support should this be required. Therefore, if the client experiences future post trauma problems then he or she is aware of when, where and how to seek help. In this instance, early intervention does not seem associated with psychiatry, and therefore those attending have not been stigmatised. It is to be hoped that this will allow 
individuals requiring further support access to available assistance without unnecessary ridicule.

Finally, the primary aim of this paper was to outline the organisation for facilitating large scale debriefings within a short time span. As such, the effectiveness of the CISDs is difficult to assess. As stated above, the team has sacrificed research methodology for the sake of maximising destigmatisation of the CISD intervention. A further paper highlighting the level of psychological problems will be considered in the future if this is pertinent. Further terrorist activity in Northern Ireland will obviously radically change current variables.

\section{Acknowledgments}

To the other member of the Stress \& Trauma team, Mrs Jean Smith. To Mr Jerry Murphy of the Royal Ulster Constabulary. To Elspeth Nicol (SSAFA Supervisor), Tracy Sims (CPN) and local support services for their help during the debriefings. Finally, to the 32 debriefers for quick response and hard work in a difficult situation.

\section{REFERENCES}

1. Foulkes SH. Group Analysis in a Military Neurosis Centre. Lancet 1946; (1): 303-307.

2. MARSHALl SLA. Island Victory. New York: Penguin, 1944.

3. FINNEGAN AP. Critical Incident Stress Debriefing in Clinical Practice. Br J Ther \& Rehab 1995; 2(12): 679685.
4. BISSON JI, DEAHL MP. Psychological Debriefing Prevention of Post Traumatic Stress: More Research Needed. Br J Psychiatry. 1994; 165: 717-720.

5. Hytten K, Hasle A. Fire Fighters: A Study of Stress $\$$ Coping. Acta Psychiatr Scand 1989; 80 (Supp 355): 5(⿸户 55.

6. ALEXANDER DA, WeLls A. Reactions of Police Officer $\stackrel{\vec{P}}{\vec{P}}$ to Body Handling after a Major Disaster. A Before an After Comparison. Br J Psychiatry 1991; 159: 547-555?

7. VASSallo DJ, TAYlor C, Aldrington D, FinNegan AP? Shattered Illusions - The Thiepval Barracks Bombing, $\Phi$ October 1996 J R Army Med Corps 1997; 143: 5-11. œे

8. DYREGRov A. Caring for Helpers in Disaster Situations:Psychological Debriefing. Disaster Management 1989 2(1): $25-30$.

9. Horowitz NJ, Wilner NR, Alvarez W. The Impact o Events Scale: a Measure of Subjective Stress Psychosom Med 1979; 41(3): 209-218.

10. GoldBerg DF, HILlier VF. A Scaled Version of the General Health Questionnaire. Psychol Med 1979; 9 t 39-145.

11. FinNEGAn AP. Societal Factors that Negatively Affeeat the Mental Health Support for the British Army \& Service Personnel Involved in Major Trauma. $J R$ Army Med Corps 1997; 143: 107-111.

12. Deahl MP, Gillham AB, Thomas J, Searl MMP SRINIVASAN M. Psychological Sequelae Following क्the Gulf War: Factors Associated with Subsequen Morbidity \& the Effectiveness of Psychologkal Debriefing. Br J Psychiatry 1994; 165: 60-65. 